\title{
IMPACTO ECONÓMICO DE LARINGOTRAQUEITIS INFECCIOSA EN UNA GRANJA DE PONEDORAS EN LIMA, PERÚ
}

\author{
ECONOMIC IMPACT OF INFECTIOUS LARYNGotracheitis in A COMMERCIAL LAYER \\ Farm in lima, Peru
}

\author{
Jessica Alvarado E. ${ }^{1}$, Eliana Icochea D. ${ }^{1,2}$, Pablo Reyna S. ${ }^{1}$, Carlos Angulo J. ${ }^{3}$, \\ Raúl Zegarra . $^{4}$
}

\section{Resumen}

El objetivo del estudio fue evaluar el impacto económico causado por la laringotraqueitis infecciosa aviar (LT) en una granja de ponedoras comerciales, ubicada en el distrito de Chilca, Lima, con una población de 14415 gallinas, que fue afectada por la LT entre agosto de 2008 hasta marzo de 2009. Se elaboró una encuesta y se recolectaron datos sobre bioseguridad, producción y costos de producción del lote afectado con LT así como de la campaña previa sin LT. El impacto económico causado por LT fue evaluado comparando ambas campañas. Se utilizó un modelo de distribución estocástica con el programa para análisis de riesgo @ RISK 5.1@. El costo por kilogramo de huevos producido en el lote afectado con LT se incrementó en 34\% comparado con el lote libre de la enfermedad; asimismo, la producción de huevos disminuyó en 16\% y la mortalidad se incrementó en $18 \%$.

Palabras clave: laringotraqueitis infecciosa aviar, impacto económico, gallinas ponedoras

\section{Abstract}

The aim of this study was to evaluate the economic impact caused by avian infectious laryngotracheitis (ILT) in a commercial layer farm located in the district of Chilca, Lima, with a population of 14415 hens that was affected by the ILT from August 2008 to March 2010. A survey was conducted and visits to the farm were done to collect biosafety and production data, and production costs of the campaign with ILT and the previous campaign without ILT. The economic impact was evaluated by comparing data from both campaigns using a stochastic distribution model with the risk analysis program @ RISK 5.1@. The cost per kilogram of eggs increased by $34 \%$, egg production declined by $16 \%$, and mortality increased by $18 \%$ in the campaign with ILT.

Key words: avian infectious laryngotracheitis, economic impact, layer

\footnotetext{
${ }^{1}$ Laboratorio de Patología Aviar, ${ }^{3}$ Laboratorio de Medicina Veterinaria Preventiva, Facultad de Medicina Veterinaria, Universidad Nacional Mayor de San Marcos, Lima

${ }^{2}$ E-mail: eliana.icochea@gmail.com

${ }^{4}$ Servicio Nacional de Sanidad Agraria, Lima
} 


\section{INTRODUCCIÓN}

La laringotraqueítis infecciosa aviar (LT) es una enfermedad respiratoria aguda, altamente contagiosa, que afecta a aves de todas las edades. Ha sido reportada en la mayoría de países del orbe, siendo común en áreas de intensa producción avícola (Jones, 2004; Guy y García, 2008). Se ha reportado en el Perú a partir de agosto de 2008 en gallos de pelea y en varias granjas avícolas (SENASA, 2009). Está considerada dentro de las Enfermedades de Declaración Obligatoria por la Organización Mundial de Sanidad Animal (OIE) y por razones de bioseguridad se prohíbe la exportación de productos y subproductos avícolas (OIE, 2005).

El virus de LT se transmite por vía aerógena, y por contacto con secreciones nasales y oculares o por fomites contaminados con secreciones de las aves afectadas (Cover, 1996; Dufour-Zavala, 2008). El virus también puede ser llevado a otras granjas libres de enfermedad a través de equipos, bandejas de huevos, vehículos, calzado y ropa; siendo el hombre el principal responsable de su diseminación entre granjas (Sellers et al., 2004). Las formas epizoóticas graves de la infección se caracterizan por signos de depresión, boqueo, expectoración de moco sanguinolento y alta mortalidad de las aves (Guy y García, 2008).

Para la prevención y control de LT es indispensable la cuarentena e higiene de la granja afectada, a fin de evitar el movimiento de personal, alimento, equipo y aves potencialmente contaminados. También se deben implementar medidas de control de roedores y perros; así como reconocer y evitar el riesgo de enfermedades persistentes originadas por parvadas de traspatio y aves de exhibición (Guy y García, 2008).

Las enfermedades en general producen importantes pérdidas económicas debido a la disminución en la producción, el incremento de mortalidad y el alto costo del tratamiento
(Jiménez, 2007). Las pérdidas económicas que produce la LT en aves de postura se deben a una elevada tasa de mortalidad (5$50 \%$ ), reducción temporal de la producción de huevos (10-50\%); retardo de crecimiento en pollitas de reemplazo, y por los gastos en medicación, los cuales se incrementan con las infecciones secundarias (Humberd et al., 2002; Manathan, 2006).

Los modelos económicos se aplican en el ámbito de la salud animal para investigar la situación económica y las consecuencias de las enfermedades en animales; siendo la simulación uno de los modelos económicos más usados (Chilonda y Huylenbroeck, 2001). El presente estudio se llevó a cabo con el fin de evaluar el impacto económico que produjo la LT en granjas de ponedoras en la zona de Lima.

\section{Materiales y Métodos}

\section{Lugar de Estudio}

El trabajo de campo se realizó en una granja de postura comercial localizada en el distrito de Chilca, provincia de Cañete, departamento de Lima. Se contó con una población de 14415 aves de la línea Hy-Line Brown en un sistema de cría en baterías. Las aves estuvieron afectadas por laringotraqueitis infecciosa aviar desde agosto de 2008 hasta marzo de 2009. El brote se inició a las 42 semanas de edad; y fue controlado inicialmente, pero volvió a emerger a las 64 semanas de edad.

\section{Recolección de Datos}

Se elaboró una encuesta, tomándose como referencia la «Ficha de información y compromiso de gestión para el fortalecimiento del sistema sanitario avícola» del Servicio Nacional de Sanidad Agraria (SENASA, 2009). La recolección de datos se hizo mediante visitas a la granja durante los meses de abril y mayo de 2009, revisándose ade- 
más, los registros de producción y costos de producción de la campaña con LT y de la campaña anterior al brote (sin LT). Asimismo, se evaluó el nivel de bioseguridad con la ayuda de la «Hoja de cálculo del puntaje de bioseguridad para granjas avícolas» del SENASA (2008).

\section{Evaluación de Parámetros Productivos}

Se determinó el porcentaje de mortalidad, número de huevos/ave alojada, porcentaje de producción, kilogramos de huevo/ave alojada, y el índice de conversión alimenticia (ICA) de las campañas arriba mencionadas.

\section{Evaluación del Impacto Económico}

Se calcularon los costos de producción total y por kilogramo de huevo de ambas campañas para determinar el impacto económico causado por LT. Para este fin, se empleó un modelo de distribución estocástica con el programa para análisis de riesgo @ RISK 5.1 ${ }^{\circledR}$ (10 000 iteracciones). Para definir las variables de entrada del modelo se usó principalmente la información de la granja, parámetros productivos de la línea (Hy-Line Brown International, 2009) y algunos parámetros señalados en la literatura científica (Sánchez, 2001; Cepero y María, 2005; Manathan, 2006). Cada variable fue manejada según el tipo de distribución a la cual se asociaba. También se introdujo en el modelo el promedio y la desviación estándar de los precios mensuales de venta por kilogramo de huevos y de gallinas.

\section{Resultados y Discusión}

El nivel de bioseguridad de la granja fue de tipo observable (nivel intermedio). Los parámetros productivos en general, y la curva de producción de huevos, obtenidos en las campañas con y sin LT se muestran en el Cuadro 1 y Fig. 1. En la campaña con LT se observó, entre la semana 41 y 45, una disminución de 90 a $70 \%$ de producción de hue- vos; y una segunda disminución de 67 a $31 \%$ a partir de la semana 62 hasta la semana 65 . Estas caídas en la producción coincidieron con la infección inicial y subsecuente recaída con LT.

El costo por kilogramo de huevo en la campaña con LT fue de 0.99 nuevos soles más que en la campaña sin LT (Cuadro 2), representando un incremento del 34\% del costo por kilogramo de huevo.

El costo por diagnóstico y tratamiento de la enfermedad fue de S/. 5,739.47, representando el $0.8 \%$ del costo de producción total; mientras que el costo de limpieza, desinfección y control de plagas se incrementó en $164 \%$ respecto a la campaña sin LT (Cuadro 2).

El programa para análisis de riesgo @RISK 5.1 ${ }^{\circledR}$ determinó que el lote afectado con LT rindió 666358 huevos menos por campaña comparado con el lote libre de LT. Esto se traduce en una pérdida de $34801 \mathrm{~kg}$ de huevos; es decir, una merma de $16 \%$ de la producción en el lote afectado. Además, la mortalidad se incrementó en $18 \%$ y el peso a la saca fue $2.2 \%$ menos en la campaña afectada con LT (Cuadro 3).

La LT es una enfermedad que ocasiona severas pérdidas económicas en la producción avícola moderna (McInerney, 1994). La mayor proporción de las pérdidas es ocasionada por el incremento de la mortalidad y la disminución de la producción de huevos (Guy y García, 2008).

El 16\% de merma en la producción de huevos registrada en el presente estudio se puede comparar con otros reportes que señalan una disminución del 6\% (Gomes, 2008) y de $30 \%$ (Barhoom, 2008). Este tipo de pérdida económica en un pequeño productor implicaría una dificultad muy grande para poder recuperarse. En el caso del presente estudio, muchas granjas se vieron afectadas por la enfermedad, lo cual trajo consigo un 
Cuadro 1. Parámetros productivos de una granja comercial de ponedoras de la línea Hy-Line Brown en campañas con y sin laringotraqueítis infecciosa aviar (LT) y su comparación con el estándar de la línea comercial

\begin{tabular}{lccc}
\hline \multirow{2}{*}{ Parámetros productivos } & \multicolumn{2}{c}{ Laringotraqueítis Infecciosa } & \multirow{2}{*}{ Estándar } \\
\cline { 2 - 3 } & Sin LT & Con LT & \\
\hline Mortalidad (\%) & 6.78 & 22.7 & 4.7 \\
$\mathrm{~N}^{\circ}$ huevos/ave alojada & 283 & 233 & 308 \\
Kg de huevos/ave alojada & 17.86 & 14.87 & 19.70 \\
Índice de conversión alimenticia (ICA) & 2.25 & 2.53 & 2.05 \\
\hline
\end{tabular}

Cuadro 2. Costos productivos y el costo de producción del kilogramo de huevo en una granja comercial de ponedoras de la línea Hy-Line Brown con y sin laringotraqueítis infecciosa aviar (LT)

\begin{tabular}{lrrrr}
\hline Egresos & \multicolumn{2}{c}{ Campaña sin LT } & \multicolumn{2}{c}{ Campaña con LT } \\
\cline { 2 - 5 } & \multicolumn{1}{c}{ S/. } & $\%$ & \multicolumn{1}{c}{ S/. } & $\%$ \\
\hline Costos directos & & & & \\
$\quad$ Costo de levante de una pollona & $172,980.00$ & 23.9 & 172.980 .00 & 24.3 \\
$\quad$ Alimento balanceado & $453,052.14$ & 62.6 & 434.160 .00 & 60.9 \\
Mano de obra & $15,600.00$ & 2.2 & 15.600 .00 & 2.2 \\
Asistencia técnica & $15,600.00$ & 2.2 & 15.600 .00 & 2.2 \\
Electricidad y agua & $11,550.00$ & 1.7 & 11.690 .00 & 1.6 \\
$\quad$ Limpieza, desinfección y control & $1,557.27$ & 0.2 & 4.112 .72 & 0.6 \\
$\quad$ de plagas & & & & \\
$\quad$ Diagnóstico y tratamiento & 0.00 & 0.0 & 5.739 .47 & 0.8 \\
\hline SubTotal & $670,339.41$ & 92.7 & 659.882 .19 & 92.6 \\
$\quad$ Costos indirectos & & & & \\
$\quad$ Depreciación* & $53,627.15$ & 7.4 & 52.790 .58 & 7.4 \\
\hline Total & $723,966.56$ & 100.0 & $712,672.77$ & 100.0
\end{tabular}

Costo por kg de huevo producido (S/.)

Costo por ave

$\mathrm{Kg}$ de huevo producido por ave

*Depreciación: $8 \%$ de costos directos 
Cuadro 3. Pérdidas económicas por merma en la disponibilidad para la venta de huevos y gallinas en una campaña con ocurrencia de laringotraqueítis infecciosa a viar

\begin{tabular}{lccc}
\hline Productos & Precio & Kg perdidos & Pérdida económica \\
\hline Huevos & S/. 3.83 & $34,801.00$ & S/. 133,287.83 \\
Gallinas & S/. 5.80 & $6,766.14$ & S/. 56,643.61 \\
\hline Total & & & S/. 189,931.44 \\
\hline
\end{tabular}

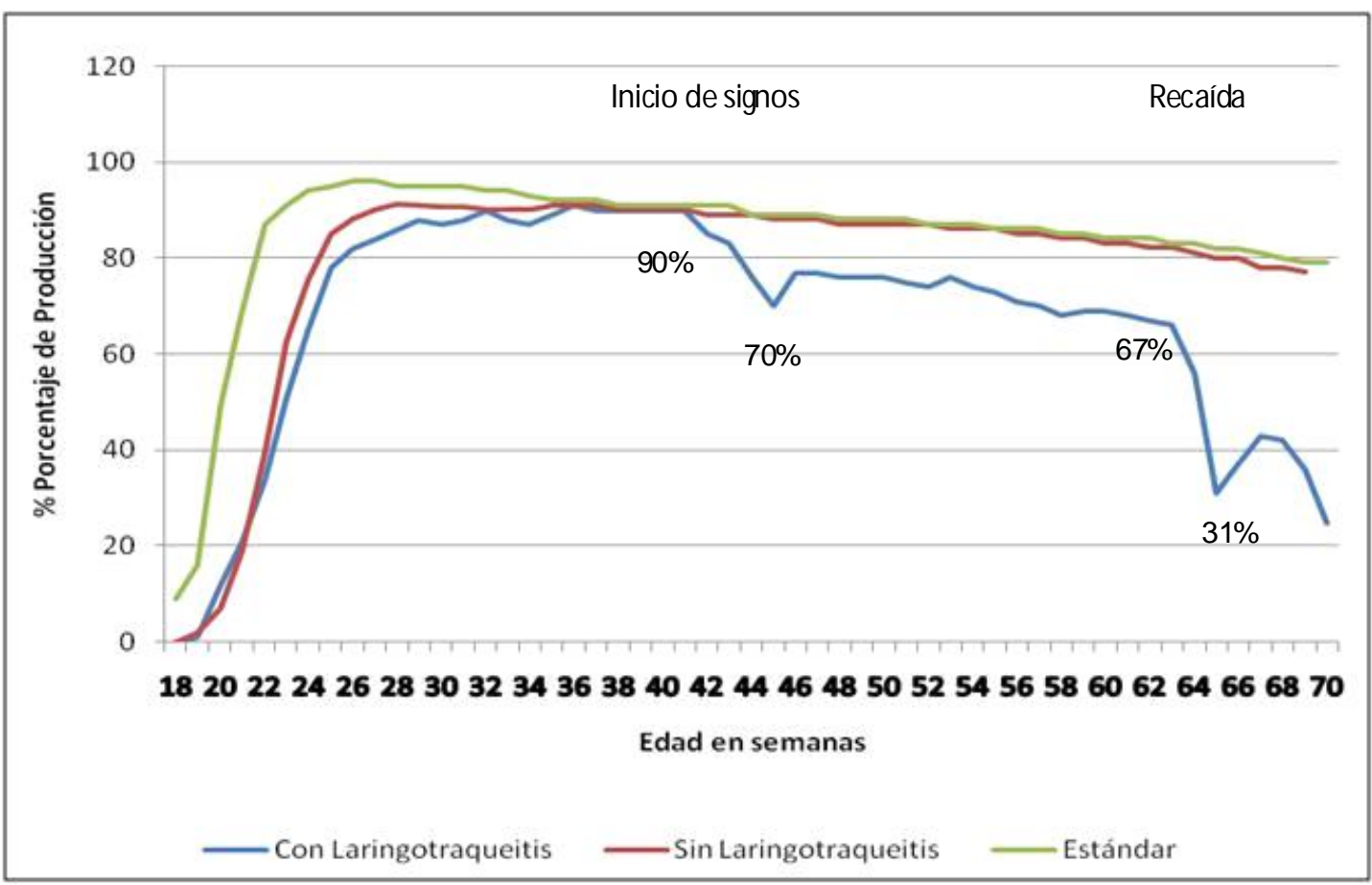

Figura 1. Curva de producción de huevos de una granja comercial con dos lotes de ponedoras de la línea Hy-Line Brown, una con y otra sin laringotraqueítis infecciosa aviar y su comparación con el estándar de la línea comercial

incremento en el precio de venta de huevos y gallinas. Según McInerney (1994), las pérdidas y gastos ocasionados por una enfermedad son, por lo general, asumidas por el consumidor, lo que ocurrió exactamente en el Perú.

\section{Conclusiones}

La laringotraqueitis infecciosa aviar en una granja de postura comercial tuvo un impacto económico negativo, disminuyendo $16 \%$ 
la producción de huevos, aumentando $18 \%$ la mortalidad de las aves y $34 \%$ el costo de producir un kilogramo de huevos, comparado con los resultados obtenidos por la campaña que no fue afectada por la enfermedad.

\section{Literatura Citada}

1. Barhoom S. 2008. Outbreak of laryngotracheitis (LT) in vaccinated commercial layer flocks in Palestine. [Internet]. Available in: www.blogs. najah.edu/.../Outbreak-of-Laryngotracheitis-LT.vaccinated-CommercialLayer-Flocks-in-Palestine/Outbreak-ofLaryngotrachetis-in-

2. Cepero BR, María GL. 2005. Jaulas convencionales y enriquecidas: comparativa. Mundo Ganadero 141: 24-30.

3. Chilonda P, Huylenbroeck GV. 2001. A conceptual framework for the economic analysis of factors influencing decision-making of small-scale farmers in animal health management. Rev sci tech Off int Epiz 20: 687-700.

4. Cover MS. 1996. The early history of infectious laryngotracheitis. Avian Dis 40: 494-500.

5. Dufour-Zavala L. 2008. Epizootiology of Infectious Laryngotracheitis and presentation of an industry control program. Avian Dis 52: 1-7.

6. Gomes F. 2008. Planejamento, implantação e administração de medidas de defesa sanitária animal para o controle da laringotraqueíte infecciosa aviária, de 2002 a 2006, na região de bastos, estado de São Paulo, Brasil. Tesis de Médico Veterinario. Sao Paulo: Universidade Estadual Paulista Campus de Jaboticabal. 157 p.

7. Guy JS, García M. 2008. Laryngotracheitis. In: Saif YM, Barnes HJ, Glisson JR, Fadly AM, Mc Dougald LR, Swayne DE (eds). Diseases of poultry. $12^{\text {th }}$ ed. Iowa, USA: Iowa State University Press. p 137-152.
8. Humberd J, García M, Ribler SM, Resurrección RS, Brown TP. 2002. Detection of infectious laryngotracheitis virus in formalin-fixed, paraffinembedded tissues by nested polymerase chain reaction. Avian Dis 46: 64-74.

9. Hy-Line Brown International. 2009. Guía de manejo comercial: Hy-Line variedad Brown. Iowa, U.S.A. [Internet]. Disponible en: www.hyline.com

10. Jiménez GV. 2007. Conceptos económicos en programas de salud animal Acovez - Asociación Colombiana de Médicos Veterinarios y Zootecnistas. [Internet].Disponible en: www. acovez.org

11. Jones $R C$. 2004. Respiratory viral diseases-lessons to be learned? Int Poultry Prod 12: 11-15.

12. Manathan P. 2006. Infectious laryngotracheitis disease situation and control measures. Poultry Ind Council 155: 1-4.

13. Mclnerney J. 1994. ¿Cuánto cuesta la enfermedad? Industria Avícola 2: 12-15.

14. [OIE] Organización Mundial de Sanidad Animal. 2005. Antigua clasificación de enfermedades de declaración obligatoria a la OIE. [Internet]. Disponible en: www.oie.int/esp/maladies/ es_OldClassification.htm

15. Sánchez IR. 2001. Evaluación de la performance productiva de un lote de postura comercial vacunado con la cepa ts 11 de Mycoplasma gallisepticum. Tesis de Médico Veterinario. Lima: Univ Nacional Mayor de San Marcos. 44 p.

16. Sellers HS, Garcia M, Glisson JR, Brown TP, Sander JR, Guy JS. 2004. Mild infectious laryngotracheitis in broilers in the Southeast. Avian Dis 48: 430-436.

17. [SENASA] Servicio Nacional de Sanidad Agraria. 2008. Laringotraqueitis en el Perú. Información oficial. Actualidad Avipecuaria 11: 50-51.

18. [SENASA] Servicio Nacional de Sanidad Agraria. 2009. Manejo de la laringotraqueitis aviar en el Perú. [Internet]. Disponible en: www.maplarevista.com/senasa2.asp 